\title{
Estabilidade físico química e microbiológica de bacon de pernil produzido com defumação natural: uma análise prática visando melhorias nos padrões de identidade e qualidade
}

\author{
Chemical and microbiological stability of bacon produced with natural smoking: A practical \\ analysis aiming at improvements in the identity and quality standards \\ Estabilidad química y microbiológica del tocino de pernil producido con ahumado natural: Un \\ análisis práctico para mejorar los estándares de identidad y calidad
}

Recebido: 25/05/2021 | Revisado: 31/05/2021 | Aceito: 07/06/2021 | Publicado: 22/06/2021

Raquel Fabian Torezan

ORCID: https://orcid.org/0000-0002-1107-4078 Universidade Tecnológica Federal do Paraná, Brasil

E-mail:raquel.fab@hotmail.com

Fábio Augusto Garcia Coró

ORCID: https://orcid.org/0000-0002-1529-6954 Universidade Tecnológica Federal do Paraná, Brasil

E-mail: fabioagc@utfpr.edu.br

Bruno Seben de Almeida

ORCID: https://orcid.org/0000-0001-6701-8166 Universidade Tecnológica Federal do Paraná, Brasil E-mail:o15bsa@gmail.com

Alexandre Rodrigo Coelho

ORCID: https://orcid.org/0000-0001-5744-5666 Universidade Tecnológica Federal do Paraná, Brasil

E-mail: arcoelho@utfpr.edu.br

Geane Duarte Nunes Pereira

ORCID: https://orcid.org/0000-0001-6996-077X Universidade Tecnológica Federal do Paraná, Brasil

E-mail: geane-duarte@ hotmail.com

Thainá Cristina Serafim

ORCID: https://orcid.org/0000-0002-3444-8546 Universidade Tecnológica Federal do Paraná, Brasil

E-mail: thainacristina@alunos.utfpr.edu.br

Bruna Araújo de Farias

ORCID: https://orcid.org/0000-0003-3696-2490 Universidade Tecnológica Federal do Paraná, Brasil

E-mail: brunaadf@hotmail.com

Dihone Henrique Organek

ORCID: https://orcid.org/0000-0003-1982-407X Universidade Tecnológica Federal do Paraná, Brasil E-mail: dihone.o@gmail.com

Eloara Gabrielli Felisbino Farias

ORCID: https://orcid.org/0000-0001-5248-6653 Universidade Tecnológica Federal do Paraná, Brasil

E-mail: eloaragabrielli@gmail.com

Mayka Reghiany Pedrao

ORCID: https://orcid.org/0000-0003-2258-1849 Universidade Tecnológica Federal do Paraná, Brasil

E-mail: maykapedrao@utfpr.edu.br

\begin{abstract}
Resumo
Em torno de $70 \%$ da carne suína consumida no Brasil é na forma de industrializados, sendo o bacon o principal. Apesar de haver informações indicativas na legislação brasileira sobre alguns padrões de identidade e qualidade para bacon, atualmente existem discrepâncias entre o que há na literatura, o que realmente é praticado nas empresas e o que os fiscais definem ideal. Em certos casos, o próprio produtor define, em conjunto com a fiscalização, os critérios para esses produtos. Assim definiu-se como objetivo desse estudo em avaliar as características de bacon produzido por de defumação natural seus padrões de identidade e qualidade visando dar subsídios para padronização de produção para frigorífico local. Foram utilizados 5 lotes de bacon de pernil com $3 \mathrm{Kg}$ cada, sendo coletados semanalmente. Esses lotes
\end{abstract}


foram acondicionados e analisados entre os períodos de 0, 30, 60 e 90 dias. Foram quantificados composição proximal, atividade de água, $\mathrm{pH}$, cor, nitrato e nitrito de sódio, cloreto de sódio e acompanhamento da oxidação lipídica durante os dias de estocagem. Em relação às análises microbiológicas foram acompanhadas durante os 90 dias de estocagem Staphylococcus coagulase positivo, Clostridium sulfito redutor e bolores e leveduras. Através das análises realizadas a conclusão é que o produto não apresenta padrão definido de produção, sendo cada lote produzido com diferentes perfis físico-químicos, todavia o controle microbiológico é eficiente. Outro aspecto relevante a ser concluído é que o tempo de vida útil não pode ser estendido, uma vez que os padrões microbiológicos e oxidativos podem ser comprometidos. Palavras-chave: Estabilidade oxidativa; Estabilidade Microbiológica; Composição proximal; Carne suína.

\begin{abstract}
Around $70 \%$ of the pork consumed in Brazil is in the form of processed meat, with bacon being the main one. Although there is indicative information in Brazilian legislation about some identity and quality standards for bacon, there are currently discrepancies between what is in the literature, what is actually practiced in companies and what the inspectors define as ideal. In certain cases, the producer himself defines, together with the inspection, the criteria for these products. Thus, the objective of this study was defined in evaluating the characteristics of bacon produced by natural smoking, its identity and quality standards in order to provide subsidies for production standardization for a local slaughterhouse. Five batches of ham bacon with $3 \mathrm{~kg}$ each were used, being collected weekly. These lots were packaged and analyzed between periods of 0,30, 60 and 90 days. Proximal composition, water activity, $\mathrm{pH}$, color, sodium nitrate and nitrite, sodium chloride and monitoring of lipid oxidation were quantified during storage days. The microbiological assessment was followed during the 90 days of storage, through counting of coagulase-positive Staphylococci, sulphite reducing Clostridia and total yeast and mold counts. Via these analyses, the conclusion is that the product does not present a defined production pattern, each batch being produced with different physical-chemical profiles, however the microbiological control is efficient. Another relevant aspect to be concluded is that the useful life cannot be extended, since the microbiological and oxidative patterns can be compromised.
\end{abstract}

Keywords: Oxidative stability; Microbiological stability; Proximal composition; Pig meat.

\title{
Resumen
}

Alrededor del $70 \%$ de la carne de cerdo consumida en Brasil se encuentra en forma de carne procesada, siendo el tocino el principal. Si bien existe información indicativa en la legislación brasileña sobre algunos estándares de identidad y calidad para el tocino, actualmente existen discrepancias entre lo que está en la literatura, lo que realmente se practica en las empresas y lo que los inspectores definen como ideal. En determinados casos, el propio productor define, junto con la inspección, los criterios para estos productos. Así, el objetivo de este estudio se definió en evaluar las características del tocino producido por ahumado natural, su identidad y estándares de calidad con el fin de otorgar subsidios para la estandarización de la producción de un matadero local. Se utilizaron cinco lotes de tocino de pierna de $3 \mathrm{~kg}$ cada uno, recolectados semanalmente. Estos lotes fueron empaquetados y analizados entre periodos de 0, 30, 60 y 90 días. Durante los días de almacenamiento se cuantificó la composición proximal, la actividad del agua, el pH, el color, el nitrato y nitrito de sodio, el cloruro de sodio y el seguimiento de la oxidación de lípidos. En cuanto a los análisis microbiológicos se siguieron durante los 90 días de almacenamiento Staphylococcus positivo coagulasa, Clostridium reductor de sulfito y mohos y levaduras. A través de los análisis realizados se concluye que el producto no presenta un patrón de producción definido, produciéndose cada lote con diferentes perfiles físico-químicos, sin embargo el control microbiológico es eficiente. Otro aspecto relevante a concluir es que la vida útil no se puede extender, ya que los patrones microbiológicos y oxidativos pueden verse comprometidos.

Palabras clave: Estabilidad oxidativa; Estabilidad microbiológica; Composición proximal; Carne de cerdo.

\section{Introdução}

A carne suína é consumida há milhares de anos devido a sua natureza adaptável e seu uso não se restringia apenas a carne, mas também a pele, ossos e pelos que poderiam servir para fabricação de ferramentas, armas e escovas (Associação Brasileira de Proteína Animal [ABPA], 2018). Como um dos maiores produtores de proteína animal no mundo, o Brasil, produziu 3,98 milhões/ton em 2019 de carne suína sendo o mercado interno responsável pelo consumo de $81 \%$ desse total, perfazendo um consumo per capita foi de 15,3 kg/habitante (ABPA, 2020).

A Instrução Normativa $N^{\circ} 21$, de 31 de julho de 2000, que trata do Regulamento de Identidade e Qualidade do Bacon, define que:

Entende-se por Bacon ou Barriga Defumada, o produto cárneo industrializado, obtido do corte da parede torácicoabdominal dos suínos, que vai do esterno ao púbis, com ou sem costela, com ou sem pele, adicionado de ingredientes e submetido ao processo térmico adequado, com defumação. (p. 13) 
No mercado brasileiro, a principal forma de consumo de carne suína é na forma de produtos industrializados. Os produtos embutidos cozidos, defumados e curados constituem cerca de $70 \%$, já os outros $30 \%$ são consumidos de forma in natura. Nos grandes países consumidores o maior consumo de carne é na forma in natura, devido aos preços menores (SILVA, 2009).

A fumaça é um dos mais antigos métodos de preservação dos alimentos. Efeitos como a desidratação superficial e a ação de compostos como fenóis e formaldeído depositados como materiais resinosos na superfície da carne têm propriedades bacteriostáticas (Roça, 2000) e contribuem para desenvolvimento de aroma, sabor e cor característicos, além de prolongar a vida útil (Adicon, 1998). No processo mais simples de defumação o produto é acondicionado em câmaras pré-aquecidas com carvão/lenha/eletricidade/gás e a madeira em um ambiente que gere fumaça. Após a deposição da fumaça no produto, o aquecimento finaliza o processo. É evidente que o alimento fica exposto a todos os componentes da fumaça, tenham ou não estes, as funções desejadas (Bliska, Viana \& Freitas, 1996).

Com o progresso na ciência identificando as substâncias ativas e os aperfeiçoamentos introduzidos nos equipamentos, a fumaça passou a ser controlada e otimizada de maneira que produza somente os efeitos desejados no alimento, eliminando-se os compostos indesejáveis. Houve o surgimento da fumaça líquida comercial, que pode funcionar como aditivo, uma vez que se apresenta numa forma estável e pronta para ser diluída e aplicada, além de ser classificada como GRAS (Generally Recognized as Safety) do FDA (Food and Drug Administration) dos Estados Unidos. Neste país, o termo "defumado naturalmente" está reservado para produtos que foram defumados por processos tradicionais e o termo "flavor de fumaça natural" para produtos que foram defumados artificialmente com a fumaça líquida que é considerada um ingrediente. O sistema de aplicação da fumaça líquida vem sendo adotado nas indústrias, particularmente nas de maior escala de produção (Maga, 2018).

Apesar do Bacon ser um produto amplamente consumido existem poucos estudos sobre as alterações que ocorrem com este produto ao longo do tempo e se estas alterações se aplicam quando o produto é defumado a quente ou a frio. A legislação nacional não estabelece parâmetros físico-químicos e microbiológicos claros do produto nos quais as empresas possam utilizar como respaldo em seu processo de produção.

Neste estudo em especial, um abatedouro frigorífico de suínos localizado no norte paranaense, sob regime de Inspeção Federal identificou a necessidade de verificar parâmetros microbiológicos e físico-químicos ao longo de um determinado período para definição da vida útil do Bacon, com a finalidade de saber se o produto necessita de melhor padronização e quais seriam suas características físico-químicas e microbiológicas. Dessa forma, a definição de padrão de identidade e qualidade passou a ser o objetivo central deste estudo.

\section{Metodologia}

\section{Procedimento metodológico}

Para o desenvolvimento deste estudo o método de abordagem da pesquisa foi quantitativo estatístico, de acordo com o proposto por Aragão \& Neta (2017), onde trata-se de um método de análise planejado por dados que permite obter de um conjunto complexo de dados que permite avaliar informações a partir de uma amostragem e fazer comparações e correlações de acordo com os objetivos propostos.

\section{Amostragem}

As amostras utilizadas para as análises foram produzidas a partir de pernil de suínos submetido a defumação natural de acordo com a Figura 1. Foram encaminhadas para o laboratório um lote produzido por semana, em um total de $3 \mathrm{Kg}$ de amostra semanal. Foram coletados cinco lotes durante o experimento. Essas amostras foram trituradas em câmara de fluxo laminar e fracionadas em embalagens tipo "zip loc" e mantidas sob refrigeração para posterior análise. Foram separadas amostras em diferentes porções, sendo estas destinadas para análises físico-químicas e microbiológicas. Todos os lotes foram fracionados em 
triplicatas para os tempos de análises de 0,30, 60 e 90 dias.

Figura 1 - Fluxograma para produção de bacon de pernil suíno por defumação natural.

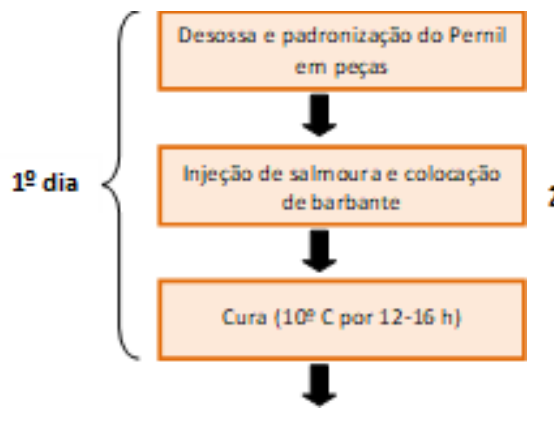

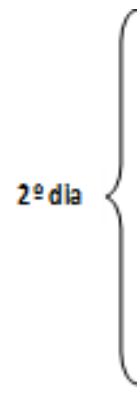

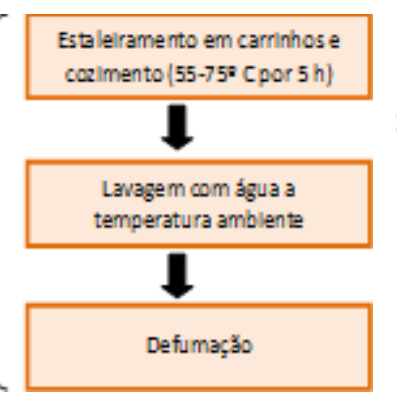

Fonte: Autores.

\section{Análises físico-químicas}

A umidade foi medida através de secagem em estufa com circulação de ar forçada a $105^{\circ} \mathrm{C}$ (Instituto Adolfo Lutz [IAL], 2008). Lipídios totais presentes foram solubilizados por éter de petróleo e determinados por gravimetria, através de balão de Soxhlet (IAL, 2008). Cinzas pela técnica de eliminação da matéria orgânica e inorgânica volátil à temperatura de $550^{\circ} \mathrm{C} \mathrm{em}$ forno tipo mufla (IAL, 2008). Para determinação das proteínas, o processo utilizado foi de Kjeldahl, baseado na determinação do nitrogênio e posteriormente convertido em proteína (IAL, 2008). A determinação do $\mathrm{pH}$ foi realizada através do método potenciométrico. Para isto, foram misturados $50 \mathrm{~g}$ de cada amostra com $10 \mathrm{~mL}$ de água destilada e realizada a leitura do $\mathrm{pH} \mathrm{em}$ um potenciômetro digital de bancada marca Tecnopon, modelo mPA-210.

Para determinar a cor do bacon a técnica utilizada baseou-se na leitura através de colorímetro (Konica Minolta® CR400, Japão), onde $\mathrm{L}^{*}$ representa a luminosidade, $\mathrm{a} *$ representa a intensidade da cor vermelha e $\mathrm{b} *$ representa a intensidade da cor amarela. A leitura foi realizada em cinco pontos e o resultado foi expresso conforme a média apresentada. Cloretos foram determinados através do Método de Möhr, onde são precipitados na forma de cloreto de prata, em meio levemente alcalino e com presença de indicador (IAL, 2008). Para avaliação da oxidação lipídica foi utilizado o método do TBARS (Substâncias reativas ao ácido 2-tiobarbitúrico) de acordo com Talardgis et al. (1964), modificado por Crackel et al. (1988), conforme as recomendações de Shahidi et al. (1985). Para a determinação do nitrato e do nitrito presentes na amostra, o nitrato foi reduzido

a nitrito em coluna de cádmio em meio alcalino. Posteriormente foi realizada a diazotação do nitrito com ácido sufanílico e copulação com cloridrato de alfanaftilamina em meio ácido formando o ácido alfa-naftilamino-p-azobenzeno-p-sulfônico. A leitura final foi realizada em espectrofotômetro (IAL, 2008). Para determinação da atividade de água no bacon foi utilizado equipamento específico para medição deste parâmetro, marca Aqualab-Decagon Devices Inc., modelo CX-2.

\section{Análises Microbiológicas}

Foram adicionados a $225 \mathrm{ml}$ de água peptonada a $0,1 \%, 25 \mathrm{~g}$ de bacon moído (10-1). Diluições decimais sucessivas até $10^{-3}$ foram realizadas pela transferência de $1 \mathrm{ml}$ da diluição anterior para $9 \mathrm{ml}$ de água peptonada a $0,1 \%$. Análise de Staphylococcus coagulase positivo foi realizado em ágar Baird Parker com solução de gema de ovo e telurito de potássio 1\%, os inóculos $\left(0,1 \mathrm{ml}\right.$ das diluições $10^{-1}$ a $\left.10^{-3}\right)$ foram distribuídos na superfície das placas e incubadas por $48 \mathrm{~h}$ a $37^{\circ} \mathrm{C}$. As colônias foram contadas e o resultado foi expresso em UFC/g. (American Public Health Association [APHA], 2015). Para determinação de Clostridium sulfito redutor foi utilizado ágar Triptose Sulfito Cicloserina (TSC), sem solução de gema de ovos. Os inóculos ( $1 \mathrm{ml}$ das diluições $10^{-1}$ a $10^{-3}$ ) foram distribuídos nas placas que foram incubadas em anaerobiose por $24 \mathrm{~h}$ a $35-37^{\circ} \mathrm{C}$; as colônias foram contadas e o resultado foi expresso em UFC/g. Para contagem de mesófilos aeróbios foi utilizado ágar padrão para 
contagem (PCA), os inóculos (1 ml das diluições $10^{-1}$ a $10^{-3}$ ) foram distribuídos no ágar e as placas foram incubadas por 24h a $37^{\circ} \mathrm{C}$, as colônias foram contadas e o resultado foi expresso em UFC/g (APHA, 2015).

\section{Análise estatística}

A análise estatística consistiu em processar os dados através do software Biostat. Os testes realizados foram análise descritiva e ANOVA, seguido de teste de médias.

\section{Resultados e Discussão}

Os resultados obtidos para determinação de umidade podem ser observados na Tabela 1. Especificamente para avaliar umidade trabalhou-se com tempo 0 e 60 dias, uma vez que se trata do tempo de vida de prateleira estipulado pelo produtor. Observa-se que existe diferença significativa nos valores de umidade entre as amostras, que foram produzidos em períodos diferentes, totalizando 5 lotes. Todos os lotes no tempo inicial apresentaram teores de umidade diferentes, o que indica que não há padronização em relação à produção, ou seja, não existe um valor específico de água livre no produto que possa definir qual o valor médio de água aceitável no processo de defumação. O que se sugere é trabalhar com um valor entre o mínimo e máximo obtido, ou seja, 44 a $64 \%$ de umidade para bacon de pernil.

Tabela 1 - Análise de umidade para tempo inicial e final de armazenamento, realizada em triplicata, para bacon de pernil produzido por defumação natural. Valores médios, seguidos de desvio padrão.

\begin{tabular}{l|cc}
\hline & \multicolumn{1}{|c}{ Inicial } & Final \\
\hline Lote 1 & $55,86(1,69)^{\mathrm{bA}}$ & $53,66(1,40)^{\mathrm{bA}}$ \\
Lote 2 & $44,36(1,65)^{\mathrm{dB}}$ & $48,10(1,41)^{\mathrm{cA}}$ \\
Lote 3 & $56,97(1,35)^{\mathrm{bA}}$ & $57,98(0,35)^{\mathrm{aA}}$ \\
Lote 4 & $64,15(1,63)^{\mathrm{aA}}$ & $54,78(4,53)^{\mathrm{abB}}$ \\
& $49,51(1,74)^{\mathrm{cA}}$ & $48,45(1,29)^{\mathrm{cA}}$ \\
\hline
\end{tabular}

Letra minúsculas nas colunas, quando iguais indicam que não há diferença significativa a 5\%. Letra maiúsculas nas linhas, quando iguais, indicam que não há diferença a 5\% de significância. Fonte: Autores.

Para melhor acompanhamento da presença de água no produto, a determinação do teor de umidade foi repetida ao final do tempo de vida útil definido pelo produtor, ou seja, 60 dias. Foi observado que não houve um padrão de comportamento entre os lotes, havendo lote com elevação e outros com queda desses valores. Isso pode ser observado entre as linhas da Tabela 1. Em artigo de Torres et al. (2000) o resultado divulgado para umidade de bacon é de 26,49\%, todavia esses autores não indicam se o produto é oriundo de panceta ou pernil, bem como o método de defumação e secagem.

Segundo dados apresentados por Crippa (2010) os valores para umidade foram entre 53,78 a 56,41 para o tempo 0 de produção e de 54,78 a 55,29 para o tempo de 60 dias de armazenamento, indicando que não há diferença significativa entre 
tempo inicial e final de armazenamento. Por outro lado, Alves (2007), relata que produtos cárneos defumados podem variar entre 2 a $6 \%$ sua umidade. As variações obtidas nesse experimento foram de 2,14\% para o Lote 5 até $14 \%$ para o Lote 4 , sendo, portanto, maiores do que o relatado por Alves (2010).

Se houvesse essa possibilidade de padronizar a umidade do produto entre um intervalo de valor aceitável de umidade, de acordo com a legislação (Brasil, 2000), haveria a possibilidade de haver um produto com características semelhantes entre os lotes, fato esse de importância considerável para a fidelização os consumidores, além de facilitar a definição de padrões de identidade e qualidade para esse tipo de bacon.

De acordo com Kulchaiyawat et al. (2009) indicam que a atividade de água de bacon pode variar de 0,85 a 0,94. Dados fornecidos por Schmidt e Fontana Jr (2019) são de 0,968. Fiorda e Siqueira (2009) obtiveram atividade de água de 0,939. Os dados obtidos nesse experimento estão de acordo com o obtido na literatura, todavia é necessário ressaltar que há variação considerável na atividade de água entre os lotes, o que se verificou para umidade e que mais adiante será observado em outros pontos a serem discutidos.

Tabela 2 - Análise de atividade de água realizada em triplicata, para bacon de pernil produzido por defumação natural. Valores médios, seguidos de desvio padrão.

\begin{tabular}{l|ccc}
\hline & T0 & T60 & T90 \\
\hline Lote 1 & $0,939( \pm 0,003)^{\mathrm{d}}$ & $0,939( \pm 0,004)^{\mathrm{d}}$ & $0,940( \pm 0,001)^{\mathrm{d}}$ \\
Lote 2 & $0,944( \pm 0,001)^{\mathrm{c}}$ & $0,958( \pm 0,004)^{\mathrm{c}}$ & $0,961( \pm 0,003)^{\mathrm{c}}$ \\
Lote 3 & $0,964( \pm 0,001)^{\mathrm{b}}$ & $0,961( \pm 0,005)^{\mathrm{c}}$ & $0,968( \pm 0,004)^{\mathrm{b}}$ \\
& & & \\
Lote 4 & $0,967( \pm 0,001)^{\mathrm{a}}$ & $0,970( \pm 0,001)^{\mathrm{b}}$ & $0,969( \pm 0,001)^{\mathrm{b}}$ \\
Lote 5 & $0,965( \pm 0,005)^{\mathrm{a}, \mathrm{b}}$ & $0,972( \pm 0,001)^{\mathrm{a}}$ & $0,973( \pm 0,002)^{\mathrm{a}}$ \\
\hline
\end{tabular}

Letra minúsculas nas colunas, quando iguais indicam que não há diferença significativa a $5 \%$.

Fonte: Autores.

Quando o tema é proteína total em carnes sabe-se que existem vários trabalhos que relatam a temática. Cita-se, por exemplo, que Marçal et al. (2016) indicam valores médios para carne de pernil suíno fresco de 21,32\%. Outros autores tais como Skobrák e Bodnár (2012) enquanto Klimiene e Klimas (2010) obtiveram 19,10\% e 23,42\%, respectivamente, de proteínas para carnes frescas de suínos. Comentário interessante nesse contexto foi realizado por Skobrák e Bodnár (2012) dizendo que o conteúdo proteico de suínos é resultado de vários fatores e menos estável quando comparado a outros animais, sendo, portanto, mais suscetível a grandes variações. Esse último comentário é perfeitamente pertinente para este trabalho, uma vez que foi notado uma heterogeneidade na matéria prima, resultando em um produto diferenciado para cada lote em relação a sua constituição.

Kulchaiyawat et al. (2009) obtiveram valores para proteínas totais em bacon entre 10,6 a 15,20\%, já Crippa (2010) obteve uma média de $21 \%$. Essas diferenças podem ser explicadas pelo tipo de bacon, sendo esse produzido à base de panceta (barriga) ou lombo de suíno. O presente trabalho apresenta dados compatíveis com Crippa (2010) e não há variações 
significativas entre os valores proteicos para os Lotes 1 a 5.

Tabela 3 - Análise de proteína total, lipídio, cinzas e cloretos, realizados em triplicata, para bacon de pernil produzido por defumação natural. Valores médios, seguidos de desvio padrão.

\begin{tabular}{c|cccc}
\hline & Proteína total & Lipídios & Cinzas & Cloretos \\
\hline Lote 1 & $22,82(2,02)^{\mathrm{a}}$ & $15,47(1,34)^{\mathrm{c}, \mathrm{d}}$ & $4,32(0,16)^{\mathrm{b}}$ & $0,30(0,04)^{\mathrm{b}}$ \\
Lote 2 & $21,50(0,85)^{\mathrm{a}}$ & $14,74(1,32)^{\mathrm{d}}$ & $5,05(5,06)^{\mathrm{a}}$ & $0,37(0,03)^{\mathrm{a}}$ \\
Lote 3 & $20,82(2,11)^{\mathrm{a}}$ & $16,42(1,44)^{\mathrm{c}}$ & $4,03(0,12)^{\mathrm{c}}$ & $0,31(0,07)^{\mathrm{b}}$ \\
& & & & \\
Lote 4 & $19,68(3,77)^{\mathrm{a}}$ & $20,25(0,66)^{\mathrm{b}}$ & $2,96(0,18)^{\mathrm{d}}$ & $0,17(0,01)^{\mathrm{d}}$ \\
& & & & \\
Lote 5 & $22,58(1,61)^{\mathrm{a}}$ & $30,80(0,69)^{\mathrm{a}}$ & $2,60(0,18)^{\mathrm{e}}$ & $0,21(0,02)^{\mathrm{c}}$ \\
& & & & \\
\hline
\end{tabular}

Letra minúsculas nas colunas, quando iguais indicam que não há diferença significativa a $5 \%$. Fonte: Autores.

Para lipídios totais (Tabela 3) para carne de suíno magro há dados fornecidos por Lowe et al. (1990), um teor médio de 19,4\% e Kempster et al, (1986) relatam 24,3\%. Ainda para carne de suíno comercial foi obtido valor médio de 15.07\$3.47 por Skobrák e Bodnár (2012). Todavia os valores relatados para lipídios totais presentes em bacon são tão diversificados quanto os da matéria prima, o que acaba sendo uma consequência. Valores para gordura total em bacon foram obtidos por Brewer et al. (1994) havendo variação entre 29,1 a 39,1\%. Baker (1956) relata que bacon de pernil apresentou de 31 a $36 \%$ enquanto o de pancetta apresentou 56\% de lipídios totais. Kulchaiyawat et al. (2009) obtiveram para diferentes tipos de bacon, valores entre 16,45 a 55,95\%. A Tabela 3 demonstra os teores de lipídios totais obtidos no presente estudo. Como relatado para proteínas, também há variações significativas entre os lotes, indicando realmente que a padronização do material lipídico é dificultada, uma vez que isso está associado à própria matéria prima.

Segundo Silva (2000) o objetivo de avaliar o pH dos alimentos auxilia na avaliação da microbiota predominante, ajuda na compreensão da natureza dos processos deteriorativos que poderão ocorrer, bem como a intensidade e os parâmetros do processamento térmico a que possa ser submetido. Para valores de pH Kulchaiyawat et al. (2009) indicam valores entre 5,90 a 6,25. Crippa (2010) obteve pH entre 5,90 e 6,01 para bacon de pernil. Fiorda e Siqueira (2009) obtiveram valores de pH de 5,50. Analisando os dados da Tabela 4 pode-se comparar os valores de $\mathrm{pH}$ para bacon de pernil entre os lotes e dentro dos lotes pelo período de tempo. Observou-se que houve diferença significativa entre os lotes para os valores de $\mathrm{pH}$ para os três tempos de armazenamento, todavia com o passar do tempo os valores de $\mathrm{pH}$ tenderam a diminuir, como observado nos Lotes 3,4 e 5 . O mesmo não ocorreu para os Lotes 1 e 2. Essas alterações podem causar comprometimento associados a estabilidade de cor e microbiologia do produto com o decorrer do tempo de armazenamento. 
Tabela 4 - Análise de pH realizada em triplicata, para bacon de pernil produzido por defumação natural para tempos 0,60 e 90 dias de armazenamento. Valores médios, seguidos de desvio padrão.

\begin{tabular}{c|ccc}
\hline & T0 & T60 & T90 \\
\hline Lote 1 & $6,03(0,02)^{\mathrm{cB}}$ & $6,18(0,04)^{\mathrm{bA}}$ & $6,21(0,05)^{\mathrm{aA}}$ \\
Lote 2 & $6,04(0,06)^{\mathrm{cA}}$ & $6,04(0,05)^{\mathrm{cA}}$ & $5,99(0,3)^{\mathrm{bA}}$ \\
Lote 3 & $6,27(0,01)^{\mathrm{aB}}$ & $6,42(0,04)^{\mathrm{aA}}$ & $5,80(0,03)^{\mathrm{cC}}$ \\
Lote 4 & $6,18(0,04)^{\mathrm{bA}}$ & $6,22(0,04)^{\mathrm{bA}}$ & $6,06(0,04)^{\mathrm{bB}}$ \\
& & & \\
Lote 5 & $6,03(0,03)^{\mathrm{cA}}$ & $6,00(0,01)^{\mathrm{cA}}$ & $5,92(0,01)^{\mathrm{bB}}$ \\
\hline
\end{tabular}

Letra minúsculas nas colunas, quando iguais indicam que não há diferença significativa a 5\%. Letra maiúsculas nas linhas, quando iguais, indicam que não há diferença a 5\% de significância. Fonte: Autores.

Agências internacionais tais como a Food and Drug Administration (FDA) tendem a organizar-se contra a presença de nitrosaminas em produtos cárneos, e buscam há anos reduzir esses níveis, sendo esse movimento um padrão mundial (Havery \& Fazio, 1985). No Brasil, a legislação define limites máximos de 0,015g/100g e 0,03g/100g, respectivamente para nitrito e nitrato de sódio, para carnes e produtos cárneos, denominados estes produtos como conservantes (Brasil, 1998).

Em relação aos valores para nitrato e nitrito de sódio, a formulação usada nesse experimento teve a adição de 3,3\% de sal de cura, com valor inicial, assim processado, em média de 253 ppm de nitrito de sódio para os lotes analisados. Na Figura 2 se observa o comportamento no processo de redução desse sal, uma vez que com o tempo de armazenamento o nitrito é gradativamente convertido em nitrato de sódio. Os valores decaem para 168, 104 e 70mg para 30, 60 e 90 dias, respectivamente. Dessa forma o residual desse sal está de acordo com os parâmetros exigidos pela legislação brasileira que é de 150ppm.

Figura 2 - Box plot para valores de nitrito de sódio em bacon de pernil durante período de armazenamento de 30, 60 e 90 dias. As linhas vermelhas indicam as médias dos lotes analisados.

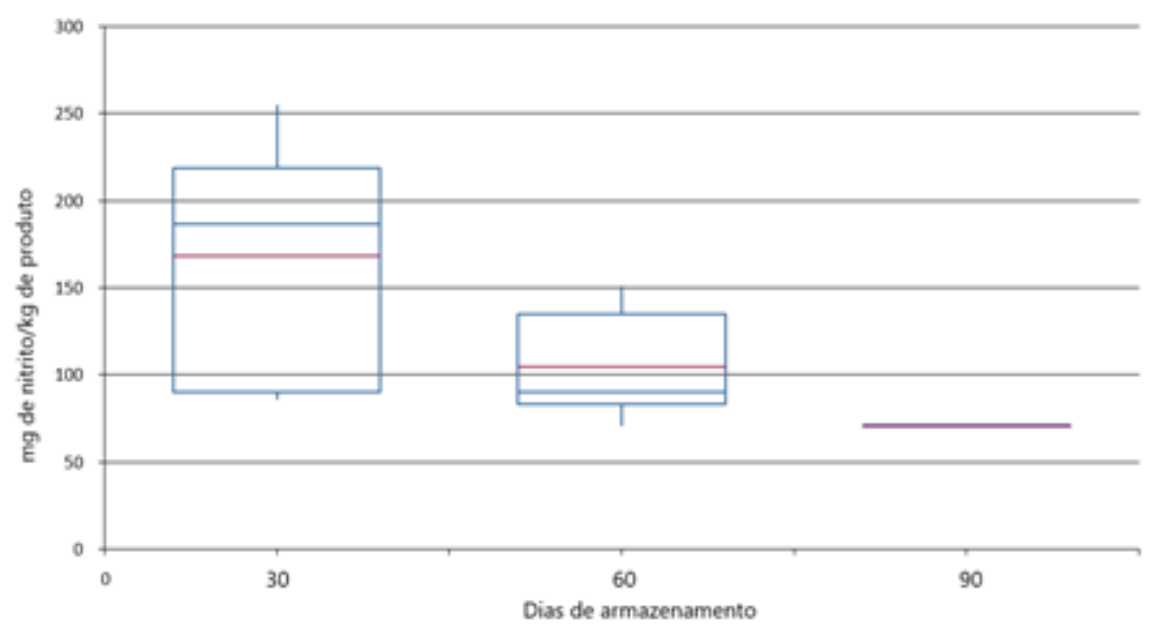

Fonte: Autores. 
Como o bacon é um produto com uma quantidade significativa de gordura e sua embalagem não é uma barreira para deter troca gasosa, mesmo com a adição de sais de cura, há a necessidade de acompanhamento da velocidade das taxas de oxidação lipídica deste produto. O produto em questão tem em sua formulação ao mesmo tempo elementos pró oxidantes e antioxidantes, tais como cloreto de sódio e sal de cura, respectivamente.

Segundo Bai et al., (2017), o valor para TBARS de carne suína fresca é de aproximadamente 0,2 mg MDA/kg, e comenta que em trabalho realizado por Han et al., (2006) a qualidade sensorial da carne começa ser comprometida quando a concentração de TBARS atinge valores próximos de 0,46 mg MDA/ $\mathrm{kg}$ e com 1,2 mg MDA / $\mathrm{kg}$ a qualidade sensorial está completamente comprometida, impossibilitando o consumo do produto.

Para bacon, todavia sem mencionar tratar-se de pernil ou panceta, Coronado et al., (2002) obteve valores de 0,11 a 1,82 mg de MDA/Kg entre 0 e 16 semanas de armazenamento a -20C, ou seja, mesmo a essa temperatura houve uma elevação em 16 vezes nas taxas de oxidação lipídica, indicando o quão instável oxidativamente é esse produto, mesmo na presença de sais de cura.

A Figura 3 indica os resultados obtidos para a avaliação da oxidação lipídica do bacon de pernil com defumação natural analisado nesta proposta. Observou-se que os valores obtidos estão acima dos obtidos para carne in natura, todavia quando comparados a outros trabalhos com bacon não são similares. Uma provável justificativa seja pela temperatura de armazenamento, uma vez que o atual experimento foi conduzido em temperatura de refrigeração e não de congelamento, o que não é um obstáculo para a aceleração das fases de propagação da oxidação lipídica.

Figura 3 - Box plot para valores analisados em cinco lotes de substâncias reativas ao ácido tiobarbitúrico (TBARS) em bacon de pernil durante período de armazenamento de 0,15, 30, 60 e 90 dias. As linhas vermelhas indicam as médias dos lotes analisados.

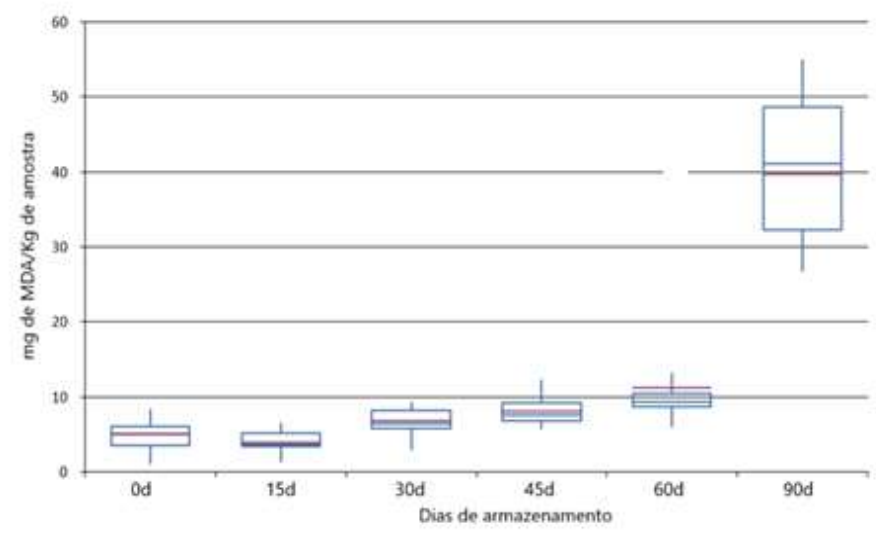

Fonte: Autores.

A Figura 4 por sua vez é uma representação da dispersão dos dados dos valores de TBARs de uma forma mais explícita, de maneira a compreender a elevação no processo de oxidação. Normalmente o prazo de validade estabelecido pelos frigoríficos para bacon é de sessenta dias, o que é respaldado com essa avaliação. Entre o período de sessenta para noventa dias de armazenamento há um salto significativo nos valores de malonaldeído, o que, sensorialmente falando, pode ser um ponto final para a comercialização do produto. Para maiores detalhes, uma análise sensorial poderia ser realizada para corroborar os elevados valores com notas de atributos sensoriais de aceitação. Em artigo publicado por Queiroga et al., (2020) onde estudaram hambúrgueres formulados com bacon e carne de caprinos, os valores de TBARs foram elevados desde o tempo zero, sendo eles 
10,63 a 11,43mg de malonaldeído/kg de produto para 0 a 40 dias de estocagem respectivamente.

Figura 4 - Distribuição dos dados obtidos para os em cinco lotes de substâncias reativas ao ácido tiobarbitúrico (TBARS) em bacon de pernil durante período de armazenamento de 0,15, 30, 60 e 90 dias.

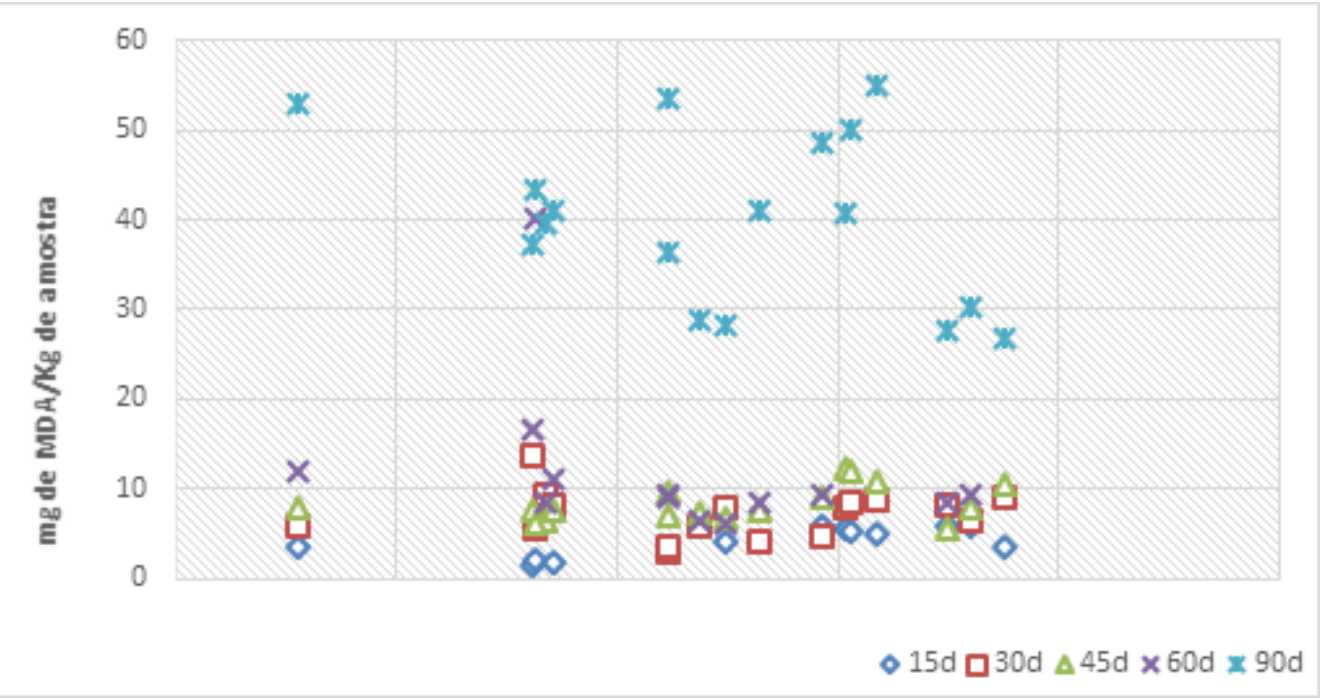

Fonte: Autores.

Os parâmetros de cor que foram medidos $\mathrm{L}^{*}$ indica luminosidade de 0 (preto) a 100 (branco), a* intensidade da cor vermelha/verde e $b^{*}$ intensidade da cor amarela/azul (Figura 5). Os valores de L* não apresentaram diferença significativa a $5 \%$ por análise de teste de médias (Tukey) ao longo dos 90 dias de armazenamento. O mesmo ocorreu para valores de a*, todavia os valores de $b^{*}$ fora significativamente diferente ao longo do período de armazenamento. Esses dados podem ser visualizados nas Figuras 5,6 e 7, respectivamente. Isso indica que mesmo com fatores negativos para fatores de oxidação e mesófilos aeróbicos no tempo de 90 dias, o parâmetro cor é estável ao longo do tempo. O valor de b* sofreu elevação com o aumento do período de armazenamento.

Figura 5 - Valores de $a^{*}, b^{*}$ e $L^{*}$ para bacon de pernil produzido por defumação natural para tempos 0 , 60 e 90 dias de armazenamento. Valores médios (círculos), seguidos de desvio padrão (linhas).
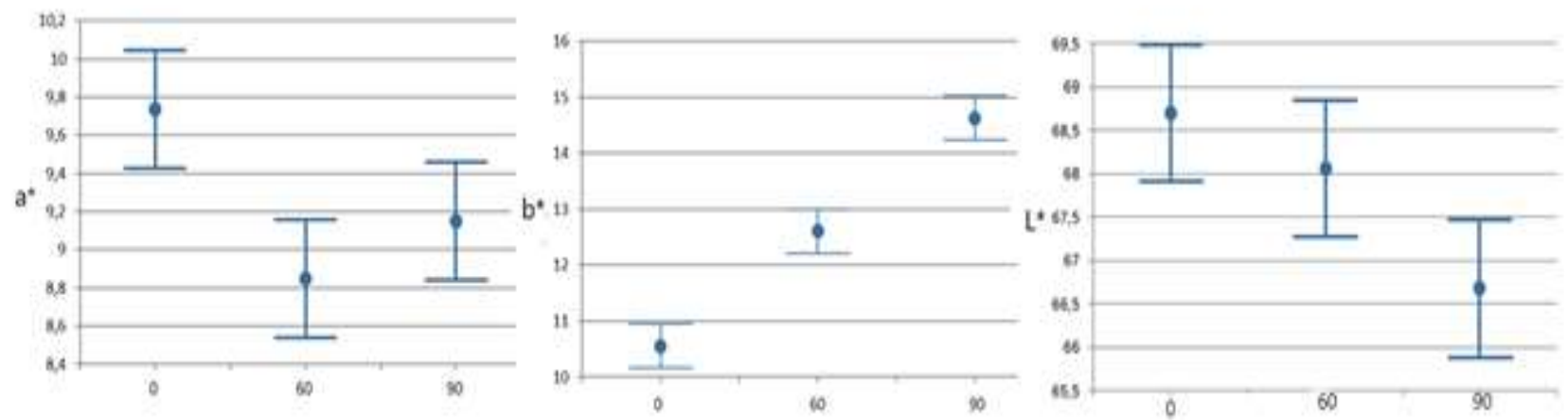

Fonte: Autores.

Em relação às análises microbiológicas, as amostras testadas não apresentaram crescimento para os microrganismos no período de 90 dias. Conforme a Tabela 5, em todos os 5 lotes de Bacon recebidos não houve crescimento significativo de colônias 
e/ou colônias características.

Tabela 5 - Resultados das análises microbiológicas para bacon de pernil produzido sob defumação natural, ao longo dos 90 dias.

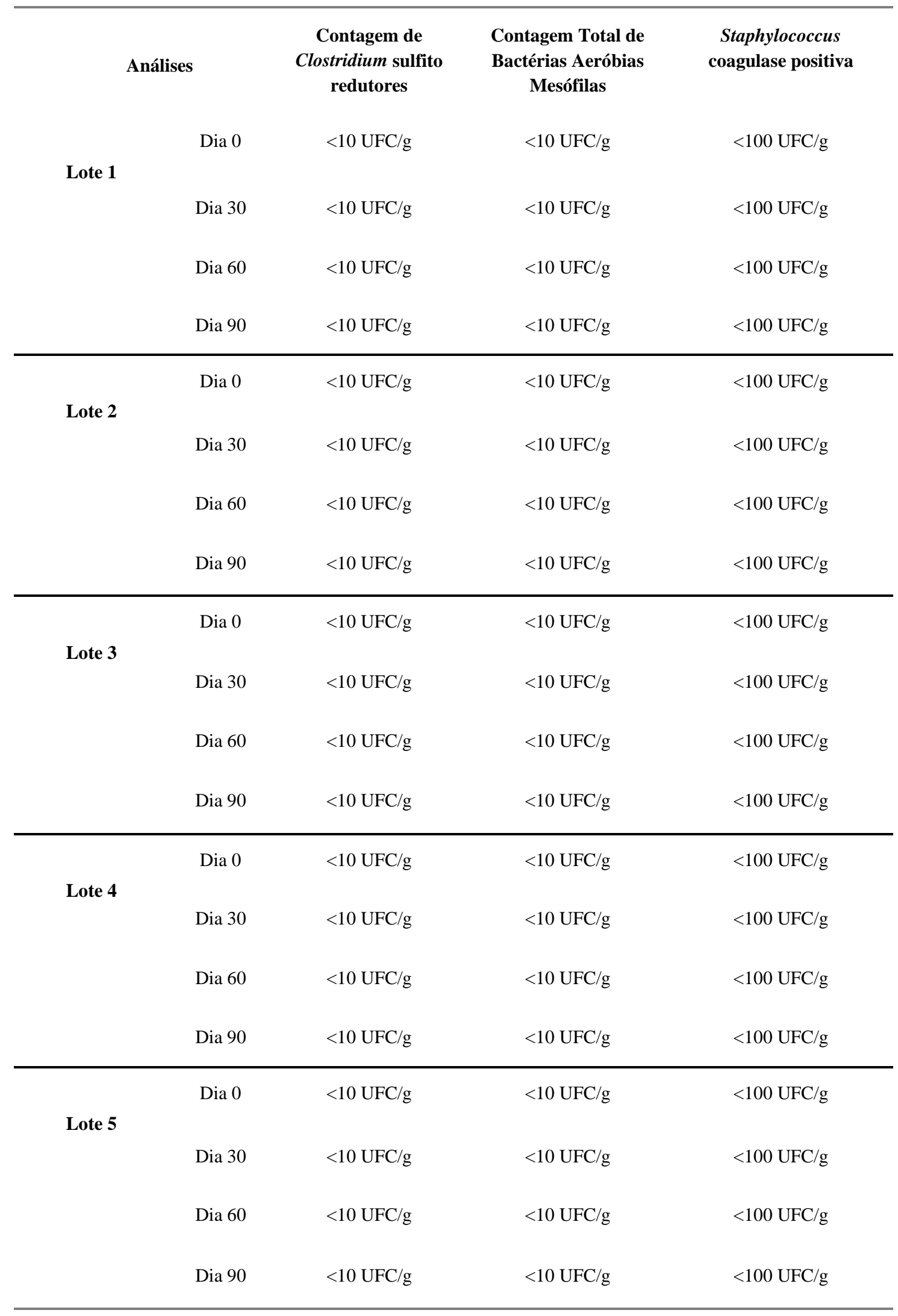


Ao longo das análises foi observado que os lotes de bacon se mantiveram estáveis por 60 dias, todavia com 90 dias de armazenamento foi possível identificar que as amostras começaram a apresentar crescimento de bolor, porém mesmo apresentando bolor após o $3^{\circ}$ mês não houve crescimento significativo de colônias e/ou colônias características. Durante os primeiros 60 dias o produto se manteve estável, como era esperado e de acordo com a validade do fabricante. Após este período, houve crescimento de bolores que, quantificados ainda assim, apresentavam-se de acordo com a legislação brasileira vigente, todavia houve início de crescimento microbiano que deverá ser considerado para futuros tempos de armazenamento.

Com os resultados obtidos pode-se fazer algumas correlações ao tipo de processamento deste produto, uma vez que a defumação, tipo de embalagem e uso de sais de cura tendem a impedir ou diminuir o crescimento de microrganismos patogênicos. Resultados semelhantes foram encontrados por Taormina e Bartholomew (2005) ao inocularem culturas de Staphylococcus sp. em barrigas inteiras, submeterem ao resfriamento em tempos e temperaturas diferentes, onde concluiu-se que o processo de defumação a quente, além de diminuir a umidade superficial, produz fenóis que atuavam como antimicrobianos.

O uso de sais de cura com ação de conservante e antimicrobiano é bastante difundido, uma vez que possui ação bastante eficiente, baixo custo e aumenta a vida de prateleira devido a ação antimicrobiana. O'leary e Solberg (1976), investigaram a atividade das enzimas gliceraldeído-3-fosfato desidrogenase (GAPDH) e Aldolase em células de Clostridium perfringens com atividade inibida pelo nitrito de sódio, observaram que a GAPDH foi totalmente inibida, enquanto a Aldolase teve sua atividade diminuída em $67 \%$, sugerindo que a interação entre o nitrito e grupos sulfidrílicos possuem o efeito de inibição enzimática e consequente função antimicrobiana quando usado em produtos.

Outro fator que se deve levar em consideração é o modo de embalar o produto, uma vez que embalagens fechadas à vácuo inibem o crescimento de bactérias aeróbias. Segundo Sheard (2010), o vácuo extrai o ar, a embalagem se ajusta a carne e o oxigênio residual é utilizado para reações do tecido. Essa falta de oxigênio faz com que o padrão de crescimento microbiano seja alterado, favorecendo o crescimento de bactérias ácido lácticas, as quais não causam danos indesejáveis

\section{Conclusão}

Através das análises realizadas a conclusão é que o produto estudado não apresenta um padrão definido de produção, sendo cada lote produzido com diferentes perfis físico-químicos, todavia o controle microbiológico é eficiente. Outro aspecto relevante a ser concluído é que o tempo de vida útil do produto não pode ser estendido, uma vez que os padrões microbiológicos e oxidativos podem ser comprometidos, sendo assim este permanece em sessenta dias.

Como o bacon é um produto de difícil padrão de homogeneização, uma vez que a própria matéria prima é variável, recomenda-se que estudos desse mesmo tipo sejam realizados constantemente, uma vez que há poucos dados na literatura a respeito do produto. Além disso, há bacon de panceta, que acarretará outro perfil físico-químico. Logo, estudos constantes poderiam alimentar a literatura de forma a dar suporte para que haja um padrão de informações de modo a gerar dados que possam ser utilizados pelas indústrias e pelos órgãos reguladores.

\section{Agradecimentos}

Os autores gostariam de agradecer ao Laboratório Multiusuário do Câmpus Londrina (LabMult-LD) da Universidade Tecnológica Federal do Paraná pelas análises realizadas, especificamente pela utilização dos equipamentos Aqualab, KjeldahlTec e SoxTec. Agradecem também ao CNPq pela concessão de bolsa Produtividade em Extensão Tecnológica Nível II para a Dra MRP, e a CAPES (Coordenação de Aperfeiçoamento de Pessoal de Nível Superior) pelo suporte para o desenvolvimento dessa pesquisa. 


\section{Referências}

ABPA. (2018). Relatório anual 2018. Associação Brasileira de Proteína Animal. http://www.abpa-br.com.br/storage/files/relatorio-anual-2018.pdf

ABPA(2020).Relatório anual 2020. Associação Brasileira de Proteína Animal. https://cleandrodias.com.br/2020/wp-content/uploads/2020/05/Relatorio-ABPA2020.pdf

Alves, R.B. (2007) Importância da PSE na carne de suínos. [Trabalho de conclusão de Curso, Universidade Castelo Branco].

American Public Health Association. (2015) Compendium of Methods for the Microbiological Examination of Foods, 5. ed. APHA.

Aragão, J. W. M. de. (2017). Metodologia Científica. [recurso eletrônico]. UFBA, Faculdade de Educação, Superintendência de Educação a Distância. 51 p.

Bai, J. J., Lee, J. G., Lee, S. Y., Kim, S., Choi, M. G. \& Cho, Y. (2017). Changes in Quality Characteristics of Pork Patties Containing Antioxidative Fish Skin Peptide or Fish Skin Peptide-loaded Nanoliposomes during Refrigerated Storage. Korean journal for food science of animal resources, v. 37, n. 5, pp. 752-763. 10.5851/kosfa.2017.37.5.752

Baker, L. C. (1956) The chemical composition and nutrition value of bacon. Journal of the Science of Food and Agriculture, v. 7, 195610.1002/jsfa.2740070302

Bliska, F. M. M., Viana, A. G. \& Freitas, M. H. A. (1996). Defumação de Produtos Cárneos. Ital.

Brasil, Ministério da Agricultura, Pecuária e Abastecimento. Instrução Normativa no 21, de 31 de julho de 2000 . Regulamento para fixação de Identidade e Qualidade de Bacon ou Barriga Defumada. Diário Oficial da União, Brasília, DF, 31 jul. 2000.

Brasil. Secretaria de vigilância sanitária do Ministério da Saúde. Portaria no 1004, de 11 de dezembro de 1998, republicada no Diário Oficial da União de 22 de março de 1999. Aprova Regulamento Técnico: "Atribuição de função de aditivos, aditivos e seus limites máximos de uso para a categoria 8 - carne e produtos cárneos". http://www.anvisa.gov.br/alimentos

Brewer, M. S., Stites, C. R., McKeith, F. K., Bechtel, P. J., Novakofski, J. E. \& Bruggen, K. A. Belly thickness effects on the proximate composition, processing, and sensory characteristics of bacon. Journal of Muscle Foods, v. 6, pp. 283-296. 10.1111/j.1745-4573.1995.tb00573.x

Coronado, S. A., Trout, G. R., Dunshea, F. R. \& Shea, N, P. (2002) Effect of dietary vitamin E, fishmeal and wood and liquid smoke on the oxidative stability of bacon during 16 weeks' frozen storage. Meat science, v. 62, n. 1, p. 51-60, 2002. 10.1016/s0309-1740(01)00226-1

Crackel, R. L., Gray, J. I., Pearson, A. M., Booren, A. M. \& Buckley, D. J. (1988). Some further observations on the tba test an index of lipid oxidation in meats. Food Chemistry, v. 28, n. 3, p. 187-196. 10.1016/0308-8146(88)90050-7

Crippa, R. L. (2010). Carne suína PSE: incidência e reflexos no processo de elaboração do bacon em uma indústria do vale do taquari. [Trabalho de Conclusão de Curso, Centro Universitário Univates].

Fiorda, F. A. e Siqueira, M. I. D. (2009). Avaliação do pH e atividade de água em produtos cárneos. Estudos, vida e saúde, v. 36, n. 5/6, p. 817-826. 10.18224/est.v36i4.1132

Han, G. J., Shin, D. S., Kim, S. J., Cho, Y, S \& Jeong, K. S. (2006). Effects of propolis addition on quality characteristics of oriental medicinal seasoning pork. Korean Journal of Food Science and Technology. v. 38, p. 75-81. https://www.koreascience.or.kr/article/JAKO200603042157818.page

Havery, D.C. \& Fazio, T. (1985). Human exposure to nitrosamines from foods. Food. Technol., v. 39, p. 80-3. https://pascalfrancis.inist.fr/vibad/index.php?action=getRecordDetail\&idt=8974295

Instituto Adolfo Lutz. (2008). Métodos químicos e físicos para análise de alimentos, 4. ed. Instituto Adolfo Lutz.

Kempster, A. J., Cook, G. L. \& Grantley-Smith, M. National estimates of the body composition of British cattle, sheep and pigs with special reference to trends in fatness: A review. Meat Science, v. 17, p. 107 - 138, 1986. 10.1016/0309-1740(86)90059-8

Kliminiené, A. \& Klimas, R. (2010): The influence of the wild boar on the biological and performance traits of domestic pigs. Polish J. Natural Sci., Vol 25(2): 123-131. 10.2478/v10020-010-0010-1

Kulchaiyawat, C., Sebranek, J. G. \& Dickson, J. S. (2009). Quality Characteristics of Traditional, Natural and Organic Bacon. Animal Industry Report: AS 655, ASL R2392. 10.31274/ans_air-180814-173.

Lowe,D.B, Kempster, A. J., Fogden, M,W \& White, C.F. (1990). Chemical composition of fresh pork and bacon from pigs of different breed types, sexes and origins. The British Society of Animal Production, v. 1990. pp 55. 10.1017/S0308229600018365.

Maga, J. A. (2018). Smoke in food processing. CRC press.

Marçal, D. A., Abreu, R. C., Cheung, T. L. \& Kiefer, C. (2016). Consumo da carne suína no brasil: Aspectos simbólicos como determinantes dos comportamentos. Revista em Agronegócio e Meio Ambiente, v. 9, p. 989-1005. 10.17765/2176-9168.2016v9n4p989-1005

O`leary, V. \& Solberg, M. (1976). Effect of Sodium Nitrite Inhibition on Intracellular Thiol Groups and on the Activity of Certain Glycolytic Enzymes in Clostridium perfringens. Applied and Environmental Microbiology, v. 31, n. 2, p. 208-212.10.1128/aem.31.2.208-212.1976.

Queiroga, V. T. F.., Costa, S. dos S. ., Albuquerque, T. da N. ., Santana, A. G. de ., Silva, M. G., Marques, I. R. ., Alves, R. do N. ., \& Meireles, B. R. L. de A. (2020). Oxidative stability of goat hamburger added with black sesame extract. Research, Society and Development, 9(10), e5349108623. https://doi.org/10.33448/rsd-v9i10.8623

Roça, R. O. (2000) Tecnologia da carne e produtos derivados. Faculdade de Ciências Agronômicas, UNESP. 
Research, Society and Development, v. 10, n. 7, e29110716497, 2021

(CC BY 4.0) | ISSN 2525-3409 | DOI: http://dx.doi.org/10.33448/rsd-v10i7.16497

Skobrák, E. B.; Bodnár, K. (2012) The main chemical composition parameters of pork: review. Review on Agriculture and Rural Development, v. 1, n. 2, p. 534540. https://www.researchgate.net/publication/280775181_The_main_chemical_composition_parameters_of_pork_review

Schmidt, S. J. \& Fontana Junior., A. (2008). Appendix E: Water Activity Values of Select Food Ingredients and Products In: Water Activity in Foods: Fundamentals and Applications. 2ed. Blackwell Publishing and the Institute of Food Technologists. 10.1002/9780470376454.app6.

Sheard, P. R. (2010). Bacon. In: Toldrá, F. Handbook of Meat Processing. Wiley-Black Well, p. 327-336

Silva, J. A. (2000). Tópicos da tecnologia de alimentos. 1 ed. Varela.

Silva, J. P. \& Silva, L. P. G. (2009). Estudo e avaliação do consumidor de carne suína "in natura" e industrializada na microrregião de guarabira (PB). Agropecuária Científica no Semi-árido, v. 05, p. 57-61. 10.30969/acsa.v5i1.49.

Taormina, P. J.; Bartholomew, G. W. (2005). Validation of bacon processing conditions to verify control of Clostridium perfringens and Staphylococcus aureus. Journal of Food Protection, v. 68, n. 9, p. 1831-1839. 10.4315/0362-028x-68.9.1831.

Torres, E., Campos, N., Duarte, M., Garbelotti,, S., Philippi, R. \& Minazzi-Rodrigues, R, S. (2000). Composição centesimal e valor calórico de alimentos de origem animal. Ciência e Tecnologia de Alimentos, v. 20, 145-150. 10.1590/S0101-20612000000200003 